\title{
Stabilization of Phenomenon and Meaning
}

\section{On the London \& London episode as a historical case in philosophy of science}

\section{Jan Potters}

Received: date / Accepted: date

\begin{abstract}
In recent years, the use of historical cases in philosophy of science has become a proper topic of reflection. In this article I will contribute to his research by means of a discussion of one very famous example of case-based philosophy of science, namely the debate on the London \& London model of superconductivity between Cartwright, Suárez and Shomar on the one hand, and French, Ladyman, Bueno and Da Costa on the other. This debate has been going on for years, without any satisfactory resolution. I will argue here that this is because both sides impose on the historical case a particular philosophical conception of scientific representation that does not do justice to the historical facts. Both sides assume, more specifically, that the case concerns the discovery of a representational connection between a given experimental insight the Meissner effect - and the diamagnetic meaning of London and London's new equations of superconductivity. I will show, however, that at the time of the Londons' publication, neither the experimental insight nor the meaning of the new equations was established: both were open The author would like to acknowledge the Research Foundation - Flanders (FWO) as funding institution. Center for Philosophical Psychology, Department of Philosophy, University of Antwerp, Grote Kauwenberg 18, 2000 Antwerpen, Belgium

E-mail: Jan.Potters@UAntwerpen.be
\end{abstract}


for discussion and they were stabilized only later. On the basis of this historical discussion, I will then propose an alternative approach to the case study: the case should not be seen as a site of confrontation between pre-existing philosophical accounts, but rather as a way to historically elaborate and develop philosophical concepts. I will then show how approaching the historical episode in this way suggests an alternative approach to the philosophical study of representation, according to which it involves the establishment, over time, of a stable connection between constellations of different elements that, through discussion and engagement with alternative views and approaches, come to constitute phenomenon and meaning.

Keywords Scientific Representation · London \& London Model · Models and Theories · History and Philosophy of Science

\section{Introduction}

Philosophers of science often employ historical cases. Surprisingly, however, this widespread methodology did not receive much philosophical reflection until a few years ago, when philosophers of science interested in the relation between history and philosophy of science started to reflect on the precise role that case studies could play: can we infer general, abstract or normative philosophical claims from concrete, particular or descriptive historical cases? How are we to handle, e.g., what Katherina Kinzel calls "historiographical pluralism[, i.e.] situations of conflict between different case studies of the same historical episodes" 2016, p. 123) ? 1 In this paper, my aim is to contribute to this emerging literature by studying in detail one particular case study employed by philosophers of science, the London \& London model of superconductivity.

\footnotetext{
1 Some of the central publications in this new debate are Burian, 2001 Pitt, 2001 Burian 2002 Schickore 2011 Arabatzis\&Schickore, 2012, Kinzel, 2015) and the papers collected in (Mauskopf\&Schmaltz, 2012) and (Sauer\&Scholl, 2016).
} 
In 1995, Nancy Cartwright, Towfic Shomar and Mauricio Suárez published their famous toolbox-paper. There they argued that most philosophical conceptions of scientific models could not account for the London \& London model of superconductivity, since they all conceived of the construction of models as theory-driven, whereas this model's construction was, they claimed, phenomenologically driven: it was developed in a way that was independent from theory in method and aims. Since then, this claim has received quite some response from Steven French and James Ladyman, sometimes together with Otávio Bueno and Newton C. Da Costa, who have argued that the case does not argue against theory-driven views (French\&Ladyman, 1997; French, 1999, French\&Ladyman, 1999, DaCosta\&French, 2000, Ladyman, 2002, Bueno et al., 2002, French, 2010, Bueno\&French, 2011, Bueno et al., 2012a b) 2 Following the tradition, I will henceforth refer to these two sides as CSS (Cartwright, Shomar, Suárez) and FLBD (French, Ladyman, Bueno, Da Costa).

Here I will argue, however, that the debate on whether the model's construction was either theory- or phenomenologically-driven is misguided, since approaching the issue in terms of this distinction introduces a specific kind of philosophical presupposition that does not do justice to the historical episode. It imposes, more specifically, a particular conception of representation on the case, namely that it concerns the discovery of a representational connection between a given experimental phenomenon and the meaning of the Londons' equations. On the basis of this presupposition, CSS and FLBD then argue whether the discovery of this connection was autonomous from theory or not. I will argue, by contrast, that the historical facts do not support this presupposition, since at the time both the experimental phenomenon and the new equations'

\footnotetext{
2 The London \& London model has become a kind of topic in itself: not only CSS and FLBD, but also for example Elaine Landry (2007, p. 3), Samuel Schindler (2007), Margaret Morrison (2008 p. 75), Daniela BailerJones, (2009 p. 140), and Soazig Le Bihan (2012 p. 270) have discussed aspects of it in their work on scientific models.
} 
meaning were still open for discussion. This will then lead me to claim that the debate has not yet found a resolution because both sides approach the case as evidence that needs to decide between competing philosophical theories. If, on the other hand, we approach the case as an opportunity for further historical elaboration and development of our philosophical concepts, progress does seem to be possible. The historical episode suggests an alternative approach to representation: it indicates that it is only through a process, over time, of stabilization of both phenomenon and meaning that a consensus on a representational connection could emerge.

To accomplish this, I will proceed as follows. I will start, in section 2, with a discussion of the way in which CSS and FLBD read the London \& London case in terms of the theory-phenomenon dichotomy. In section 3 I will then show that both sides rely on a historical narrative that does not do justice to the historical London \& London episode. On the basis of this, I will then propose (section 4 an alternative approach to the historical episode, which will lead me to suggest that scientific representation is better studied as the establishment, over time, of a stable connection between constellations of different elements that come to constitute phenomenon and meaning.

\section{The Philosophical Debate on the London \& London Account of}

\section{Superconductivity}

The main target of CSS's original (1995) paper, Cartwright outlines in her part $3^{3}$ are what they call theory-driven views of science such as the syntactic and semantic conception of theory 4

\footnotetext{
3 The original article consists of two parts. The first, by Cartwright, formulates their more general philosophical position, while the second, by Shomar and Suárez, concerns the case study (1995, p. 137). Besides this article, I will also make use of later ones by Suárez $(1999)$ and Cartwright and Suárez $(2008)$. Even though not all of these articles are written by all three of them, I will still ascribe them all to CSS, following the tradition in the debate. The same holds for FLBD's articles.

4 On the syntactic view, theories are seen as collections of sentences, whereas on the semantic view, theories are described in terms of model-theoretic structures. Both offer a theory-driven view of science in the sense that
} 
Their work forms part, more specifically, of a "movement to undermine the domination of theory": instead of assuming that it is theory that provides us with scientific representations, we should focus on how scientists employ all kinds of bits of science - besides theory, she mentions instruments, mathematical techniques, methods of approximation, etc. - as tools to construct an image of the world (Cartwright et al. 1995, p. 138).

In their part, Suárez and Shomar then elaborate how they see the domination of this theorydriven conception, and how the London case argues against it. Theory, according to theorydriven views 5 provides us with idealized models that enable it to approximate different kinds of phenomena. The application of theory to a particular kind of phenomenon then consists of the introduction of correction terms in these models, as when we model a damped harmonic oscillator by adding a particular friction term to the idealized equation describing a simple harmonic oscillator. What makes such views theory-driven is that it needs to be theory that tells us which correction terms to introduce, since otherwise they would be ad hoc (Suárez, 1999, p. 177).

The London \& London case now forms an argument against such theory-driven views of scientific models, according to CSS, since it illustrates that "it is rarely the case that models of the phenomena are arrived at as de-idealizations of theoretical models" 1995, p. 142). What it offers "[i]nstead of a theory-driven view of models [is] a phenomenologically driven one" Cartwright et al. 1995, p. 137). The case does this by showing that the construction of scientific models is guided not solely by theory (Cartwright et al. 1995, p. 142).

both assume that it is theory that drives scientific research. For an overview of the debate between the syntactic and the semantic view, see (Lutz, 2017).

5 Shomar and Suárez illustrate what they take to be theory-driven views of models through a discussion of Michael Redhead's article 'Models in Physics' (1980). In a later article, Suárez (1999) makes the same claim about Ernan McMullin's article 'Galilean Idealizations' (1985). 
2.1 The London \& London Account of Superconductivity

The brothers Fritz and Heinz London were the first, according to CSS, who were able to capture the central characteristics of superconductivity in one specific model. Superconducting materials standardly display two particular characteristics: resistanceless conductivity and the Meissner effect. It was Heike Kamerlingh Onnes $(1913)$ who first showed their resistanceless conductivity, i.e. that they are characterized by nearly zero resistance and a permanent current when cooled below an extremely low critical temperature in the absence of strong magnetic fields ${ }^{6}$ The second characteristic, the Meissner effect, was first established by Walther Meissner and Robert Ochsenfeld (1933). They found that, whatever the magnetic flux inside the material before the transition to the superconducting state, afterwards it will be vanishingly small: all magnetic flux is expelled from the superconducting material (Cartwright et al., 1995, p. $143-145$ ).

Fritz and Heinz started the elaboration of their model in their $(1935 \mathrm{a})$ article 7 by pointing out that since "[e]lectric currents are commonly believed to persist in a supra-conductor without being maintained by an electromagnetic field" 8 the relation between the field strength $\mathbf{E}$ and

6 As Michael Tinkham points out, "in many circumstances we expect absolutely no change in field or current to occur in times less than $10^{10^{10}}$ years" 1996 , p. 2).

7 This was the first of a series of further articles London 1935b London\&London 1935c London 1936. $1937 \mathrm{ab}$ ).

8 At the time, both the terms 'superconductor' and 'supraconductor' were used interchangeably. 
the current density $\mathbf{J}$ has often been described in terms of the acceleration equation (1935a, p.

$71) \sqrt{9}$

$$
\Lambda \frac{d \mathbf{J}}{d t}=\mathbf{E} \quad\left[\text { with } \Lambda=\frac{m}{n e^{2}}\right]
$$

Here, $m$ denotes an electron's mass, $e$ its charge and $n$ the number of electrons per cubic centimeter ${ }^{10}$ Regarding resistanceless conductivity, the acceleration equation works perfectly, since it allows for a stationary current - a constant, i.e. non-changing, electric current $d \mathbf{J} / d t=0-$ when $\mathbf{E}=0$. According to the London brothers, however, the equation "implies more than is verified by experiment" (1935a, p. 71). To show this, they started by taking equation (1)'s curl:

$$
\nabla \times \Lambda \frac{d \mathbf{J}}{d t}=\nabla \times \mathbf{E}
$$

Appealing to Faraday's law of induction $\left(\nabla \times \mathbf{E}=-\frac{1}{c} \frac{d \mathbf{H}}{d t}\right)$ then gave the following:

$$
\nabla \times \Lambda \frac{d \mathbf{J}}{d t}=-\frac{1}{c} \frac{d \mathbf{H}}{d t}
$$

9 As examples of such proposals, the London brothers referred to articles by Richard Becker, G. Heller, and Fritz Sauter (1933), by Werner Braunbek (1934), and by Heinz London (1934). The general intuition underlying these accounts was that "since superconductors do not obey Ohm's law (steady-state current proportional to electric field) it is most natural to suppose that it is the acceleration of the current which is proportional to field" Leggett 1995. p. 924). For a normal conductor we know that a current either induces an electric field or is supported by one. Ohm's law then tells us that this current is directly proportional to the electric field: $\mathbf{J}=\sigma \mathbf{E}$, where $\sigma$ denotes the material's conductivity. For superconducting materials this cannot be the case, for there we have a current $(\mathbf{J})$ in the absense of an external field $(\mathbf{E}=0)$. It was still commonly thought, however, that there was some kind of relation between the superconducting current and electric fields, an intuition that found its expression in the acceleration equation (Suárez, 1999 p. 185).

$10 \Lambda$ is "the analog of specific resistance - i.e. a new characteristic constant depending on the material" Dahl 1992 p. 229). 
Taking into account another of Maxwell's equations, $\nabla \times \mathbf{H}=\frac{1}{c} \mathbf{J}$ (with the displacement current neglected), gave them:

$$
\nabla \times \nabla \times \Lambda \frac{d \mathbf{H}}{d t}=-\frac{1}{c^{2}} \mathbf{H}
$$

Given that Maxwell's equations also tell us that $\nabla \cdot \mathbf{H}=0$, we have:

$$
\Lambda c^{2} \nabla^{2} \frac{d \mathbf{H}}{d t}=\frac{d \mathbf{H}}{d t}
$$

Integrating with respect to time they obtained the following equation for the magnetic field $\mathbf{H}$

(where $\mathbf{H}_{0}$ denotes the magnetic field at the time $t=0$ before cooling down):

$$
\Lambda c^{2} \nabla^{2}\left(\mathbf{H}-\mathbf{H}_{0}\right)=\mathbf{H}-\mathbf{H}_{0}
$$

Equation (6) is a non-homogeneous differential equation. Its solutions for the magnetic field are given by the equation $\mathbf{H}=\mathbf{e}^{-\sqrt{\Lambda} c x}+\mathbf{H}_{0}$ Suárez, 1999 , p. 187). The exponentials $\mathbf{e}^{-\sqrt{\Lambda} c x}$ decrease very quickly with respect to the distance $x$ from the material's surface, which entails that the original, pre-superconducting magnetic field $\mathbf{H}_{0}$ remains frozen in:

\footnotetext{
The general solution means, therefore, that practically the original field persists for ever in the supraconductor. Only in a layer of $10^{-5} \mathrm{~cm}$ below the surface all disturbances take place reversibly, provided the treshold value is not exceeded. The field $\mathbf{H}_{0}$ is to be regarded as "frozen in" and represents a permanent memory of the field which existed when the metal was last cooled below the transition temperature. (London\&London, 1935a, p. 73)
}

Until a few years earlier, such frozen in fields were seen as firmly confirmed by experiment ${ }^{11}$ The Meissner effect indicated, however, that "magnetic fields under no circumstances can be found in the supraconducting phase" (London\&London, 1935a, p. 73), since after transition magnetic 11 A short discussion of the experiment by Kamerlingh Onnes and Willem Tuyn that was taken to confirm this belief can be found on page 23 
fields are in fact expelled from the material. As such, the acceleration equation could not be taken to capture the phenomenon completely. To overcome this, the London brothers claimed, the acceleration equation needed to be replaced:

One should not use a differential equation like 11 which contains too many possibilities, as it gives nature more freedom than it wants. If in reality $\mathbf{H}_{0}$ is always confined to the value zero, then this means that

$$
\Lambda c^{2} \nabla^{2} \mathbf{H}=\mathbf{H}
$$

is to be considered as a fundamental law and not to be treated as a particular integral of a differential equation in consequence of 1 . Since $\nabla \times \mathbf{H}=\frac{1}{c} \mathbf{J}$ we can write 7 in the form

$$
\nabla \times \Lambda \mathbf{J}=-\frac{1}{c} \mathbf{H}
$$

This we postulate as the fundamental equation which replaces Ohm's law in supraconductors. (London\&London, 1935a p. 73)

The superconducting current was thus no longer conceptualized in terms of the electric field $\mathbf{E}$, as in the case of the acceleration equation, but in terms of the magnetic field $\mathbf{H}$. The Londons then pointed out that both their equation (8) and the acceleration equation "possess, so to speak, the same degree of generality", since from both equation (3), which gives the rate of change of the current, could be derived (1935a, p. 74). The most important difference, the Londons claimed, was that while their equation enabled them to capture the Meissner effect, it was not possible to deduce the acceleration equation from it. Their equation did allow them, however, to derive an equation $\nabla \times\left(\Lambda \frac{d \mathbf{J}}{d t}-\mathbf{E}\right)=0$ that is weaker than the acceleration equation, which they turned, through analyzing the equation's Lorentz invariance, into the following expression for the relationship between electric field and charge density $\rho$ :

$$
\Lambda\left(\frac{d \mathbf{J}}{d t}+c^{2} \nabla \rho\right)=\mathbf{E}
$$

That their equation does not entail the acceleration equation was not necessarily problematic, however, since there were no compelling experimental reasons to assume that the acceleration 
equation was required over and above equations (8) and (9) (London\&London, 1935a, p. 74). In this way, the London brothers obtained a model for superconductivity that captured both resistanceless conductivity and the Meissner effect.

\subsection{London \& London: The CSS-Reading}

Theory-driven views, according to CSS, assume that it is theory that tells us how to apply idealized theoretical models to particular phenomena: "[t]heories must be seen as entirely self-sufficient in the task of generating genuinely realistic representations of problem-situations" (Suárez, 1999, p. 181). On this view, CSS continue, the London brothers had two possible ways to proceed given the fact that a new model was required in light of the Meissner effect: a first option would be to construct it by "[introducing] some correction factors well motivated from the point of view of theory into the 'acceleration equation' model or its equivalent (equation (5))"; a second option would be to "go through the derivation that took us from Maxwell's equations to the 'acceleration equation' model and revise some of the physical assumptions along the way" Cartwright et al. 1995, p. 147).

According to CSS, however, the London brothers did neither. They noticed instead that the solutions to the homogeneous equation $\sqrt{7}$ are exponentials $e^{-\sqrt{\Lambda} c x}$, which decrease very rapidly when going from the material's surface to its centre. This just means, they realized, "that there is no field inside the bulk of the superconductor[, which] is precisely what the Meissner effect provides evidence for" (Cartwright et al. 1995, p. 147). This shows, according to CSS, that the transition from the old non-homogeneous equation (6) to the Londons' new equation (7) was not theory-driven, since it did not proceed via either of the two possible ways. As such, "from the point of view of the theory-driven view, the restriction to the homogeneous equation just looks ad hoc. It seems to have been contrived only to account for the Meissner effect" Cartwright et 
al. 1995, p. 148). What the case rather argues for, CSS claim, is that "[w] hat is needed is the recognition of the independence from theory, in methods and aims, of the scientific activity we have come to call phenomenological model building" (1995, p. 148).

What CSS take to be phenomenological model building is elaborated in later articles (Suárez, 1999 Cartwright\&Suárez, 2008). Before the discovery of the Meissner effect, CSS claim, superconductors were conceived as similar to ferromagnets, materials that, when magnetized, can display magnetic behavior even in the absence of any magnetic field 12 This was a consequence of the fact that resistanceless conductivity was taken to be the primary characteristic of superconductors: "just as a ferromagnet exhibits a magnetic dipole moment in the absence of any supporting magnetic fields, a superconductor exhibits a permanent current even if unsupported by electric fields" (Suárez, 1999, p. 185). And it was this ferromagnetic conception that, according to CSS, gave rise to accounts of superconductivity in terms of the acceleration equation (Suárez, 1999 , p. 185).

The Meissner effect now did two things, according to CSS: first, it pointed out that the acceleration equation and its underlying ferromagnetic conception were problematic; and second, it also guided the London brothers towards a new conception. It showed, more specifically, that superconductors are rather diamagnets of some kind. In contrast to ferromagnets, such materials do not display any retention of magnetic properties in the absence of the external magnetic field, because diamagnetism is "associated with the tendency of electrical charges to shield the interior of a body from an applied magnetic field" (Suárez, 1999, p. 186) ${ }^{13}$

This diamagnetic insight now led the Londons to their new equations as follows, according to CSS. The acceleration equation, based on the ferromagnetic conception, allowed for $\mathbf{H}_{0}$ to be 12 Feynman (1964 chpt. 36) and Kittel (2005, chpt. 12) offer insightful accounts of what ferromagnetism comes down to.

13 Feynman (1964, chpt. 34) and Kittel 2005 chpt. 11) offer good discussions of what diamagnetism comes down to. 
part of the solution of equation (6). If we conceive of superconductors as diamagnets, however, we expect the magnetic field $\mathbf{H}_{0}$ to be expelled during the transition. In this way, the diamagnetic insight pointed out that the correct set of solutions for $\mathbf{H}$ should in fact exclude the value $\mathbf{H}_{0}$ - otherwise the initial field remains "frozen in" - and that they should only contain the exponentials $\mathbf{e}^{-\sqrt{\Lambda} c x}$ : "the Londons' diamagnetic model suggests that the field inside the material once the transition has occurred decreases very quickly with the distance $x$ from the surface of the material" (Suárez, 1999, p. 188). These are exactly the solutions of the homogeneous equation $\Lambda c^{2} \nabla^{2} \mathbf{H}=\mathbf{H}$, which led the London brothers to their equation (8) (Suárez, 1999, p. 186).

This transition was phenomenologically driven, according to Suárez (1999), since the diamagnetic insight should be seen as an autonomous entity, independent from theory, that mediates between the Meissner effect and electromagnetic theory. CSS take it to be autonomous because it displays the following four characteristics: (i) it was not derivable from electromagnetic theory, but was rather "motivated directly by the phenomena" (1999, p. 182); (ii) it went further than merely describing the empirical data 1999 , p. 183); (iii) it conveyed particular or local knowledge of the phenomenon studied, i.e. "that a superconductor is a kind of diamagnet" 1999 , p. 186) ${ }^{14}$ This autonomous entity then played a role as mediator because (iv) it offered a way to fill in the abstract, idealized models provided by the Maxwell equations for the electric and magnetic fields involved in superconductivity 1999 , p. 188) 15 Hence, the model was constructed in a non-theory-driven way: it was not electromagnetic theory but the diamagnetic insight that

\footnotetext{
14 By local or particular knowledge, CSS mean knowledge that is not part of a larger theoretical whole: "a me-
} diating model mediates between high level theory and the world by conveying some particular or local knowledge specific to the effect or phenomenon that is being modelled" 1999 p. 170).

15 The notion of a mediating model was first presented in the Models as Mediators-volume (Morgan\&Morrison. 1999), of which Suárez's article is a part. While different authors stressed different aspects of the concept, all of them conceived of models as autonomous entities that mediate between theory and phenomena. The volume's general aim was to collect instances of, and reflection on, models playing essential roles in scientific practice that were separate from any role they play in constituting theory (Cartwright\&Suárez, 2008, p. 64). 
guided this process. In this way, CSS take the case to form an argument against the view "that a good theory will in general already contain $[\ldots]$ the good representative models that it spawns" (2008, p. 64).

\subsection{London \& London: The FLBD-Interpretation}

The main target of FLBD throughout the years (see the references on page 3 ) has been the following CSS-claim:

\footnotetext{
$[\mathrm{W}] \mathrm{e}$ feel that we have stumbled upon an example of phenomenological model building about which the theory-driven view has little to say. What is needed is the recognition of the independence from theory, in method and aims, of the scientific activity that we have come to call phenomenological model building. (Cartwright et al. 1995, p. 148)
}

The problem, according to FLBD, is that theory did play an important role. For the London episode provides us with "a case of theory change, but [...] not one in which an entire model was overthrown and a completely new one constructed phenomenologically; rather, extensive and fundamental correspondences exist between the models" (French\&Ladyman, 1997, p. 377). A first, general correspondence between the earlier acceleration model and the Londons' new equation was in fact furnished by Maxwell's equations, which "play a central role in the derivation of the fundamental equation (8)" (French\&Ladyman, 1997, p. 381). Within this general theoretical context there were also more specific theoretical correspondences. In particular, FLBD refer to the role played by equation $(3) \nabla \times \Lambda \frac{d \mathbf{J}}{d t}=-\frac{1}{c} \frac{d \mathbf{H}}{d t}$, which is derivable both from the acceleration equation (see page 7) and from the Londons' new equation, by differentiating it with respect to time (French\&Ladyman, 1997, p. 380). As we have seen on page 9, it is this equation that directed the London brothers to their equation for the relationship between electric field and charge density which is weaker than the acceleration equation. 
FLBD take these correspondences to indicate that, contrary to what CSS claim, the transition from the old equation to the new one was not independent from theory in methods and aims. They show, more specifically, that theory played an important heuristic role by suggesting analogies for the development of the new model. And theory could play this role because of the experimental discovery of the Meissner effect, which "drove [...] a shift in the over-riding analogy, from that with ferromagnetism in the case of the old 'pre-Meissner' model, to that with diamagnetism in the case of London and London's" (Bueno et al. 2012a, p. 44). The Meissner effect showed the London brothers, more specifically, which parts of the old account had to be retained because they were well-confirmed (equation 3) and which had to be rejected because they went beyond experiment (the acceleration equation). On the basis of this result, the analogy then allowed for the importation of particular claims from the theory of diamagnetism, which guided the London brothers in the development of their new account (French\&Ladyman, 1997, p. 384).

The analogy also acted as a "valuable heuristic" in the Londons' later work on a theory of superconductivity (French\&Ladyman, 1997, p. 388). Following Fritz London's characterization of his work with his brother, FLBD claim that the 1935-paper provided a macroscopical interpretation, an account of the observable characteristics in terms of the standard electromagnetic field quantities, that provided a sketch for a microscopical framework, i.e. a theoretical explanatory scheme that accounts for how the phenomenon arises (1997, p. 386). This macroscopical diamagnetic interpretation "delineated a microscopical programme, in the sense of 'reducing' the range of theoretical possibilities" (French\&Ladyman, 1997, p. 388).

As such, FLBD conclude, the London case should not be read as an argument in favour of phenomenologically- over theory-driven views: it is not the case that the new account was constructed independently of theory in methods and aims. Theory in fact played an important role, according to FLBD, in both its initial development and further elaboration. 


\section{Evaluating the London \& London Debate}

\subsection{Historically Evaluating the Shared London \& London Narrative}

The previous section shows that CSS and FLBD more or less agree on the historical narrative underlying the London debate. This narrative goes as follows 16

\footnotetext{
The discovery of the Meissner effect led the Londons to see superconducting materials as diamagnets rather than as ferromagnets, which brought them to their new equations 8 and $(9$ to replace the acceleration equation.
}

The discussion also makes clear that the most salient difference between CSS and FLBD exactly concerns the way in which we should philosophically interpret the diamagnetic result of Meissner and Ochsenfeld's experiment: what kind of knowledge did it deliver, and how did this guide the London brothers? According to CSS, the brothers proceeded in a phenomenologically driven piecemeal way, because the experiment provided the particular or local knowledge, autonomous from theory, that "a superconductor is a kind of diamagnet" 1999 , p. 186). According to FLBD, the brothers proceeded in a theory-driven way because the experiment provided the structrural knowledge that an account of superconductivity should be analogous to the theory of diamagnetism.

Hence, the debate between CSS and FLBD turns on the question what kind of knowledge Meissner and Ochsenfeld's experiment provided. It is this question that the case needs to answer, in order to provide a decision between theory-driven and phenomenologically-driven accounts of models. As such, we see how both sides approach the London \& London episode as an issue of

\footnotetext{
16 Both sides also state this explicitly. Thus, CSS point out that "[m]ost of the original documents referred to by French and Ladyman are the same as those that we used in the 4-year long study that led to our account; and their reading of the history is the same as ours and as Gavroglu's and Dahls on the points at issue" (2008, p. 69). And in their latest articles, FLBD state that the main difference is maybe primarily of a philosophical nature (Bueno et al. 2012a p. 46) (Bueno et al. 2012b, p. 103).
} 
representation: how did the Londons obtain a model of superconductors that represented not only their resistanceless conductivity but also the Meissner effect? The problem, however, is that there are good historical reasons to doubt the shared historical narrative, as I will argue now.

Meissner and Ochsenfeld's Experiment A first point concerns the assumption that it was Meissner and Ochsenfeld's experiment that guided the London brothers. The London brothers themselves pointed out that other elements besides that experiment equally well played an important role in the construction of their model 17

Until recently the existence of "frozen in" magnetic fields in supraconductors was believed to be proved theoretically and experimentally. By Meissner's experiment, however, it has been shown that this point of view cannot be maintained. It results clearly from the thermodynamic discussion of Gorter that at the transition to the supraconducting state any magnetic field which may have existed before in the conductor is pushed out of it so that experiments which seemed to show that magnetic fields are frozen in are to be explained by the existence of non-supraconducting inclusions, in which the magnetic lines of forces are pressed together. (London\&London, 1935a p. 73; emphasis added)

London \& London referred here to a few articles published by Cornelius Jacobus Gorter $1933 \mathrm{a}$ 1933b) and one by Gorter together with Hendrik Casimir (1934). The importance of this thermodynamic work is also shown by the fact that Fritz London "confided to Casimir that the work of Gorter and Casimir had exerted considerable influence on the Londons' work: 'and if one had to give historical evidence, I [i.e. Fritz] would feel obliged to refer explicitly to those works that were really decisive for us" (Gavroglu, 1995, p. 121; original emphasis). This gives reason to doubt that the Londons' work was guided primarily, or solely, by the result of Meissner and Ochsenfeld's experiment, as CSS (2008, p. 65) and FLBD (2012a, p. 44) presuppose.

Ferromagnetism and the Acceleration Equation A second point concerns the assumption, by both CSS (1999, p. 185) and FLBD (1997, p. 382), that what Meissner and Ochsenfeld's experiment 17 An interesting side remark is that Suárez 1999 p. 188), in quoting this passage from the London brothers, stops right before the emphasized part. 
showed was that the acceleration equation was problematic because it conceived of superconductors in ferromagnetic terms. There are good reasons to doubt that there necessarily was such a strong connection between the acceleration equation and the ferromagnetic conception, and that it was because of this connection that the acceleration equation was to be rejected.

For one, the acceleration equation and the ferromagnetic analogy were formulated for very different purposes: while the first concerned the superconducting current's penetration depth (Dahl, 1992 p. $174-175)$, the second was intended to integrate the phenomenon of superconductivity into a fundamental theory of conduction in general (Dahl, 1992, p. 151). Moreover, they were also formulated at different times: while the ferromagnetic analogy was proposed by Felix Bloch in 1928, the acceleration accounts referred to by the Londons (see footnote 9 ) were all proposed around the time of Meissner and Ochsenfeld's publication, and while some of them predated the results by a few months, others were in fact formulated "to fit [the Meissner-Ochsenfeld result] into Maxwell's electrodynamics" (Gavroglu, 1995, p. 118). Moreover, as Dahl points out, Heinz London worked on an acceleration account after Meissner and Ochsenfeld's experiment, work which proved very fruitful for the development of their (1935a) account (Dahl, 1992, p. 228). Finally, Meissner and Ochsenfeld themselves closed their paper in which they presented their experimental results with the suggestion of an analogy between ferromagnetism and superconductivity 1933 , p. 120).

All this indicates that we can question the assumption that Meissner and Ochsenfeld's experimental results showed that the acceleration equation should be rejected because it was based on a ferromagnetic conception of superconductivity.

The Diamagnetic Insight A final issue is the assumption by both CSS (1999, p. 186 - 187) and FLBD 2012a p. 43 - 44) that Meissner and Ochsenfeld's experiment showed that superconduc- 
tors are (similar to) diamagnets, and that this insight guided the London brothers to their new equations 18

This clashes, for example, with the Londons' (1935a) article, where the brothers only referred to a diamagnetic conception at the very end of their article, after the presentation of their two equations (London\&London, 1935a, p. 88). A similar claim is found in Fritz London's (1935b) Royal Society lecture, where he stated that the fact that they characterize superconductors in terms of their new equation (8) "means that the total supraconductor is regarded as a single big diamagnetic atom" (1935b, p. 27). And in another joint article on superconductors and diamagnetism as well, Fritz and Heinz stated that it was their new equations that led to a diamagnetic characterization of superconductors 19

These claims all give us reason to doubt that Meissner and Ochsenfeld's experiments provided a diamagnetic insight which then guided the London brothers to their new equations. They suggest, more specifically, that we should remain agnostic for now about what came first, since it could equally well have been the other way around, i.e. that the Londons' new equations suggested that superconductors could be (similar to) diamagnets. The precise way in which the

\footnotetext{
18 I prefer to use the more neutral terms 'insight' or 'conception' when talking about the diamagnetic idea, rather than 'analogy' or 'knowledge', since the question of how to characterize the insight is exactly what is at issue between CSS and FLBD. As will become clear, I do not think that approaching the results of Meissner and Ochsenfeld's experiments in this way, i.e. in terms of the knowledge it provides, does justice to the case. I would like to thank an anonymous reviewer for pressing me on this point.

19 The original, in German, goes as follows: "Durch die Gleichung $8[\nabla \times \Lambda \mathbf{J}=-\mathbf{H} / c]$ wird der Supraleiter gekennzeichnet als ein einziges grosses diamagnetisches Atom" (London\&London, 1935c, p. 348).
} 
Londons saw the relation between their new equations and diamagnetism will be discussed in more detail in the next section 20

\subsection{Correcting the shared London \& London Narrative}

The previous section indicates that the historical narrative employed by CSS and FLBD as a case for their respective philosophical positions is problematic. This raises the question whether the London \& London episode can still act as a case within the debate on scientific representation. For if the historical episode is significantly different from the narrative employed by CSS and FLBD, then how can it still function as a case in favour of either theory-driven or phenomenologicallydriven accounts of scientific models? Can the London \& London episode still teach us anything about scientific representation?

My starting point to address these issues is the observation that both CSS and FLBD view the London \& London episode as a particular instance of their respective general philosophical views on representation: the case argues for, and is a concrete illustration of, the philosophical theory. They work, more specifically, under what Jutta Schickore has called the confrontational approach to the history and philosophy of science $(H P S)$, which sees history as providing evidence for deciding between different philosophical theories (2011, p. 468). Both sides assume that the historical case can, and should, provide an answer to what kind of knowledge Meissner and Ochsenfeld's experiment provided precisely, and this will then act as evidence in favour of either a theory-driven or a phenomenologically-driven view of representation.

\footnotetext{
${ }^{20}$ A few years later Fritz London did draw a direct link between the Meissner effect and diamagnetism: "Meissner and Ochsenfeld found in 1933, that a supraconductor behaves not only like an ideal conductor, but in addition also like a very strong diamagnetic metal" (1937a p. 793). This is something that will be discussed in footnote 42 on page 33 I would like to thank an anonymous reviewer for pushing me to specify this point.
} 
The main issue with this approach, as Schickore and others have argued, is that it gives rise to the following problem, well-known in the literature since Joseph C. Pitt's (2001) paper: if one chooses a case study in order to back up an already formulated philosophical claim, then there is the danger of selection bias, since one could well pick out only aspects in favour of the claim; and if one develops a philosophical claim on the basis of a historical case, then there is the danger of unwarranted generalization, since all one can rely on is this one particular case.

In order to overcome this issue, several historically-minded philosophers of science have proposed an alternative approach to the use of historical cases in philosophy of science. On this view, developed by Schickore and others, the concrete historical episode and the more abstract philosophical claim are developed in response to each other, instead of the one serving as a readymade argument for the other. As Raphael Scholl and Tim Räz put it: "we start thinking of a cyclical process: just as abstract concepts help us to understand concrete episodes, so concrete episodes help us to further elaborate our conceptual tools. On [this] view, doing HPS consists in a repeated cycling between the concrete and the abstract" (2016, p. 76). I therefore propose to return to the London \& London episode so as to clarify the issues raised in the previous section, in order to find a way to start articulating alternative philosophical concepts. As I will show in the final section, the philosophical concepts tentatively worked out on the basis of the historical study can then serve as indications for further historical research, thus providing an argument for Hasok Chang's claim that "[h]istory-writing can be a very effective method of philosophical discovery" (2012, p. 111) 21

21 Proposals similar to Schickore's are made by (Chang 2012, Kinzel 2015, 2016 Pietsch, 2016 Scholl\&Räz 2016. Knuuttila\&Loetgers, 2016). Some of them argue that we should completely abandon the confrontational model, and use history merely to develop our philosophical concepts, not as evidence for philosophical theories. Others claim that the distinction should not be seen in such absolute terms: the use of case studies in philosophy is, on their view, both evidential and hermeneutic, i.e. it can serve both to argue for general philosophical claims and to elaborate a better understanding of them. My aim here is not to argue for either of these two options. The 
Meissner and Ochsenfeld's Experiment A first question that needs to be addressed is how we should understand the role of Meissner and Ochsenfeld's experiment. As the quote on page 16 shows, this requires a closer look at how the Londons interpreted Gorter and Casimir's thermodynamic work. A good starting point for this is the following passage from a letter from Fritz London to Casimir in 1937:

\footnotetext{
The paper by Gorter, and that of Gorter and yourself, made a strong impression on me at that time, and incited me to engage myself with superconductivity. It is true that the Meissner effect could have been predicted from Gorter's ideas. The fact that the development of things did not take place this way and needed an experimental push, always appeared to me a sign that the acceptance of the reversibility was not at all self-evident, because of the fact that all experiments displayed hysteresis and other nonreversibilities. It was at that time only a hypothesis that was constructed in the dark ... and it was not proper to interpret in exactly that manner the objective non-reversibility and to pinpoint in that particular manner the assumption of reversibility. This is why the verification of this magnetothermic phenomenon seems to be so important for me. Because it means something more than a mere verification of thermodynamics. It also means, as far as I know, the verification that what we assumed to be reversible is indeed reversible. Gavroglu, 1995, p. 121)
}

The central point of both Meissner and Ochsenfeld's experiment and Gorter and Casimir's thermodynamic work, according to Fritz London, was what he called the superconducting state's reversibility. This state is characterized by two critical tresholds: the critical temperature $T_{C}$ and the critical magnetic field $H_{C}$. Taking it as irreversible, i.e. the opposite of reversible, would mean that its state of magnetization "is not uniquely determined by the external conditions, but depends on the cyclic history leading to those conditions" (Dahl, 1992, p. 167) 22 More specifonly point I wish to make is that, as it stands, the debate between CSS and FLBD has been conducted primarily in terms of the confrontational model, and that therefore, employing the alternative hermeneutic approach could help us in furthering the debate.

22 Dahl 1992 p. $164-167)$ offers an extensive account of the irreversibility-idea, with very insightful illustrations. He also contrasts it, in a very clear way, with the idea of reversibility 1992 , p. 179 - 181). See also (Matricon\&Waysand, 2003, p. 55). 
ically, two different 'histories' of how the superconducting state could be brought about were distinguished before the work of Meissner and Ochsenfeld, Gorter and Casimir, and London and London.

The first proceeds by first cooling the sample below $T_{C}$ in the absence of any magnetic field $\left(T<T_{C} ; H=0\right)$, and then exposing it to a magnetic field with a value below $H_{C}\left(T<T_{C}\right.$; $\left.H<H_{C}\right)$. In this case, the persistent currents arising on the sample's surface entail that the net magnetic flux density in the sample's interior is zero, while outside it will differ from zero Dahl, 1992 , p. $165-166)$.

In the second history, we first expose the sample at room temperature to a field below $H_{C}$, leaving the flux to penetrate $\left(T>T_{C} ; H<H_{C}\right)$. If we then cool it below $T_{C}$, we obtain a state that is very different from the one in the other history with the same external conditions $\left(T<T_{C} ; H<H_{C}\right)$, since in this case the flux density in the interior remains unchanged and is thus different from zero. When we then remove the applied field $\left(T<T_{C} ; H=0\right)$, we again obtain persistent currents, which maintain the flux inside, resulting in the sample's permanent magnetization: we have a frozen-in field (Dahl, 1992 , p. $166-167)$.

The acceptance of these two different histories entailed that the transition to the superconducting state at the time was seen as irreversible: the sample's magnetization in the states $\left(T<T_{C} ; H=0\right)$ and $\left(T<T_{C} ; H<H_{C}\right)$ is not determined by the external conditions, but depends on whether we first cool and then apply the field or vice versa (Dahl, 1992, p. 167).

That this view was generally accepted was a consequence, as the London brothers pointed out in their (1935a) paper, of the fact that "[u]ntil recently the existence of "frozen-in" magnetic fields in supraconductors was believed to be proved theoretically and experimentally" (London\&London, 1935a, p. 73) (this quote is discussed on 16. In his Paris Lectures 1937b, p. 9) Fritz London later specified that they were referring to experiments on a hollow sphere performed by Kamerlingh Onnes and Tuyn (1924). These were "long regarded as prima facie evidence for 
the frozen-in flux expected classically from Lippmann' ${ }^{23}$ perfect conductor subject to a changing field" Dahl, 1992, p. 110) ${ }^{24}$ especially because right after their publication, H. A. Lorentz (1924) showed that they could be understood in terms of Maxwellian electrodynamics. This entailed that "this physical assumption [of frozen-in fields] was being regarded as so self-evident that there was no systematic experimental study of the predicted phenomenon" (Gavroglu, 1995, p. $112)$.

It was now about this second history that Meissner and Ochsenfeld claimed that their experiments raised doubts: "[a]ccording to previous views, the field line pattern would be expected to remain unchanged if, without altering the external magnetic field $\left[\left(T>T_{C} ; H<H_{C}\right)\right]$, the temperature was lowered below the transition temperature $\left[\left(T<T_{C} ; H<H_{C}\right)\right]$. Our investigations on tin and lead [...] contradict this view" (Meissner\&Ochsenfeld, 1933, p. 181) ${ }^{25}$ The internal magnetic flux distribution did not remain unchanged but was rather expelled. This indicates that for both histories there is zero magnetic flux inside the superconductor when $\left(T<T_{C} ; H<H_{C}\right)$, and that there is therefore no difference in magnetic behavior between the two histories: "[t]he state of magnetization depends only on the external conditions of the field and temperature,

23 Dahl is referring here to Gabriel Jonas Lippmann, who is famous for Lippmann's rule, a rule that was long thought to govern the behaviour of all superconductors: "The rule, published by Lippmann in 1919, was actually stimulated by [Onnes'] 1914 experiments and is simply the consequence of Maxwell's electrodynamics for perfect conductors. It states that the magnetic flux linking any closed circuit within a body of zero resistance [...] cannot change; circulating currents are induced on the surface so as to create a magnetic flux density in the interior that cancels the flux density due to the applied field" 1992 p. 102). For a technical discussion of Lippmann's theorem, see (Essen\&Fiolhais 2012, p. $165-166)$.

24 Dahl offers an extensive account of these experiments, and the discussion that followed when they were presented in 1924 1992 p. 106 - 110). It turned out, however, that these experiments were misleading, because of the hollowness of the sphere (Dahl, 1992 p. 164), which made it difficult to carry out precise measurements (Matricon\&Waysand, 2003, p. 55).

25 Dahl 1992 p. $177-181)$ offers an extensive discussion of the context and the material set-up of these experiments. 
not on the sequence leading to those conditions" (Dahl, 1992, p. 180). In this way, the London brothers took Meissner and Ochsenfeld's experiment to point towards the reversibility of the superconducting state:

$[T]$ he elementary phenomenon of the pure supraconducting state should be considered as a very much simpler matter; according to Meissner's experiment, it looks as though the transition from the nonsupraconducting to the supraconducting phase in a magnetic field is microscopically reversible, so far as the magnetic flux can be considered as equal to zero in any volume element of the pure supraconducting phase, independently of the way in which the threshold has been passed. (London, 1935b, p. 26)

Important here, however, is that the Londons only took the experiment to point to this result in combination with Gorter and Casimir's work (see the quotes on pages 16 and 21). This work showed, more specifically, that the transition to the superconducting state could be studied thermodynamically, i.e. as a reversible phase transition ${ }^{26}$

In the preceding paragraphs we have tried to give a consistent thermodynamical treatment of the transitions from the supraconductive state to the normal state, supposing $B$ to equal zero in the supraconductive state. From the validity of Rutgers' equation 27 we concluded, that apparently the second law of thermodynamics applies to the transition. This result suggests, that the transition is essentially reversible, which would mean, that, whenever a part of a body becomes supraconductive, such persisting currents are started, that the external field will be screened off, in order that $B=0$ inside the supraconductive part. Gorter\&Casimir, 1934, p. 318)

26 Gorter and Casimir's motivation for studying the phenomenon thermodynamically derived from different theoretical and experimental investigations of superconductivity: they referred to work by Willem Hendrik Keesom and J. N. van den Ende, Wander Johannes de Haas and collaborators, Meissner and Ochsenfeld, and de Haas and Josina M. Casimir (Gorter\&Casimir 1934, p. 306 - 307).

27 One thermodynamic characteristic of the phenomenon of superconductivity is that the transition does not involve any change of latent heat (i.e. energy required to change the state — gas, liquid, solid — of the material) or of volume, but only of specific heat (i.e. energy required to change a unit mass of the material by one unit temperature). In 1934, Arend Joan Rutgers presented an equation which relates this specific heat change to the critical magnetic field (Smith\&Wilhelm, 1935, p. 261); (Dahl, 1992 p. 155). 
This now shows how both the thermodynamic work by Gorter and Casimir and Meissner and Ochsenfeld's experiments were of importance. Gorter and Casimir showed, on the assumption that $B=0$, that a thermodynamic, i.e. reversible, treatment of the phenomenon of superconductivity is possible. And what Meissner and Ochsenfeld's experiment did was to confirm this assumption: "Meissner's experiment, however, has shown that in addition the magnetic flux in a supraconductor is probably exactly zero" (London, 1935b, p. 25). In this way, these results together indicated that the phenomenon is indeed reversible.

Important to stress here is that it was only by combining Meissner and Ochsenfeld's results with Gorter and Casimir's work that the London brothers obtained this result, since the experimental results on their own were still very uncertain: the London brothers themselves pointed out, for example, that Meissner and Ochsenfeld's results indicated disappearance of the magnetic field in superconductors, "at least insofar as we can interpret this still very uncertain experimental finding in such an idealized way as it has been suggested by Gorter (1933a; 1933b) and Gorter and Casimir (1934)" (1935c p. 341; my emphasis, personal translation) ${ }^{28}$ And in his Paris lecture as well, Fritz London (1937b, p. 10) pointed out that the Meissner effect concerned ideal circumstances, which were suggested experimentally by Meissner and Ochsenfeld and some later replications by J. D. Babbitt \& Kurt Mendelssohn (1935) and J. N. Rjabinin \& Lew Schubnikow (1935) ${ }^{29}$

\footnotetext{
28 The original in German goes as follows: "wir [haben] jetzt erfahren, dass ausserdem die magnetische Induktion im Supraleiter verschwindet, wenigstens sofern wir den noch sehr unsicheren experimentellen Befund so auf einen idealen Gehalt hin interpretieren dürfen, wie es durch die thermodynamische Diskussion durch Gorter (1933a 1933b) und Gorter und Casimir (1934) nahegelegt wird".

29 The main reason for this uncertainty about the precise interpretation of the experiments was, in part, the "extreme brevity, seeming contradictions, and obvious importance" of Meissner and Ochsenfeld's paper. (Dahl 1992 p. 182). It also was a consequence, however, of the results of the first experimental attempts to replicate it. Babbitt and Mendelssohn's experiments, for example, "neither disproved the classical theory nor confirmed the Meissner effect with any certitude" (Dahl 1992 p. 189), a claim that was repeated by researchers in Toronto
} 
As such, we should not speak about Meissner and Ochsenfeld's experiment in itself delivering any kind of definite knowledge. Rather, as Matricon and Waysand (2003, p. 71) put it, "the London brothers started off by making the Meissner effect a postulate of the theory": on the basis of Meissner and Ochsenfeld's experiment, its replications and Gorter and Casimir's thermodynamical work, they started their paper by assuming that the result of Meissner and Ochsenfeld's experiment, i.e. the reversibility of the superconducting state, is indeed the ideal case.

The Acceleration Equation A second issue was that both CSS and FLBD assumed that Meissner and Ochsenfeld's experiment showed that the acceleration equation was untenable because it was based on a ferromagnetic conception. Fritz London himself pointed out, however, that the primary problem was that all existing approaches at the time assumed that, because of their resistanceless conductivity, superconductors were to be studied as Maxwellian perfect conductors 30 "the principle obstacle which stands in the way of understanding this phenomenon is to be sought in its customary macroscopical interpretation as a kind of limiting case of ordinary conductivity" $1935 \mathrm{~b}$, p. 24).

Now, the problem was not solely that "the classical magnetization of a perfect $(R=0)$ conductor (according to Maxwell) is irreversible" (Dahl, 1992, p. 165), but rather more generally that this perfect conductivity-conception gave rise to what is known as Bloch's impossibilitytheorem. The perfect conductivity view entailed that "one is bound to search for a model of the carrying out similar experiments (Dahl 1992, p. 190). And Keesom and Johannes Antonie Kok stated that Meissner and Ochsenfeld's results entailed primarily that "one must be cautious as to the appreciation of the value of the magnetic field in the neighbourhood of a supraconductor" 1934 p. 503). It was only with Rjabinin and Schubnikow (1935), who "reported perhaps the clearest confirmation of the Meissner effect", that the results started to get accepted (Dahl, 1992 , p. 193).

30 A perfect conductor is an idealized material that is characterized in terms of Maxwell's equations with infinite conductivity, i.e. zero resistance $(R=0)($ Tinkham 1996 p. 2). 
metal which, in its most stable state, contains a permanent current, and this without assistance of any external field" (London, 1935b, p. 25). This implies that one runs into trouble with a theorem from Bloch's general theory of conductivity, "according to which the stable state of any mechanism of electrons for general reasons may very probably have no current" (London, 1935b p. 25) ${ }^{31}$ for these claims together lead to Bloch's impossibility-result: the emergence of a superconducting current should in fact not be able to occur at all 2

That the issue was not primarily with the ferromagnetic analogy is now shown by the fact that this impossibility-result applied not only to the spontaneous current theory of superconductivity proposed by Bloch (and in a similar formulation by Lev Landau), which was indeed based on an analogy with ferromagnetism, but equally well to the electron latice or electron chain theory proposed by Niels Bohr and Ralph de Laer Kronig. This theory did not rely on any analogy with ferromagnetism, but it offered, as Jörg Schmalian points out, "a sophisticated version of the idea of a perfect conductor" 2011, p. 48) ${ }^{33}$ The central problem was that "it had been almost universally taken for granted that the only significant difference between a superconductor and a normal metal lay in the property of perfect electrical conductivity" (Leggett, 1995, p. 917). It was the perfect conductivity conception of superconductors, which pictured them as Maxwellian

\footnotetext{
31 The precise workings of the theorem are discussed by, among others, Smith and Wilhelm 1935 p. $266-$ 267), Dahl (1992, 151 - 153), Leggett (1995, p. 917 -918) and Schmalian (2011, p. 47). For a broader historical discussion of the theoretical study of conductivity, see Hoddeson and Baym $(1980)$ and Hoddeson et al. (1987). 32 Fritz London himself formulated Bloch's result as follows: "it is rigorously demonstrable that, on the basis of the recognized conceptions of the electron theory of metals, a theory of supraconductivity is impossible" $1935 \mathrm{~b}$ p. 24).

33 In their review article of 1935, H. Grayson Smith and J. O. Wilhelm 1935 p. 260 - 261) offered a discussion of both approaches. For more contemporary discussions, see Hoddeson et al. (1987, p. 30 - 31), Gavroglu and Goudaroulis 1989, p. $75-77)$, Dahl 1992 p. $151-153)$, Leggett (1995 p. 917), Matricon \& Waysand (2003 p. 42) and Schmalian 2011 p. $45-48)$.
} 
conductors with resistance $R=0$, that gave rise to the issue of irreversibility, frozen in fields and Bloch's impossibility result.

This now raises the question why the Londons started with the acceleration equation. The equation was first obtained by Becker, Heller, and Sauter in their work on the conduction behaviour of electrons. They proposed to take into account the way in which the electron's inertia influenced their acceleration, in order to describe the precise penetration depth of the current in a superconducting sample ${ }^{34}$ This led them to the claim that the magnetic field "decreases exponentially inside the surface of the perfect conductor" (Dahl, 1992, p. 175) ${ }^{35}$ Their work thus also relied on the perfect conductivity conception, as Becker, Heller, and Sauter themselves pointed out when they outlined how they were going to evaluate the validity of their result: "we want to investigate how the solution for superconductors obtained above results out of this solution for normal conductors with finite conductivity $\sigma$ when one takes the limit $\sigma \rightarrow \infty$ " 1933 , p. 779; personal translation) 36

It was the perfect conductivity conception that, according to the Londons, was responsible for the irreversibility idea, and hence also for the frozen-fields belief. This also applies to the acceleration account, since on this view "[o]nly in a layer of $10^{-5} \mathrm{~cm}$ below the surface all distur-

\footnotetext{
34 There was quite an interest in the penetration depth because it promised to offer more insight into the nature of superconductivity: "the penetration depth is the region where the magnetic contribution to the free energy density changes from its "normal" or "vacuum" value to that appropriate for the superconductor, and its dependence on various physical parameters can provide a sensitive test of the quantitative aspects of any theory of superconductivity" (Chandrasekhar, 1969, p. 13). One important study carried out in order to investigate the penetration depth was in fact Meissner and Ochsenfeld's experiment, since Meissner believed that this could lead to further theoretical insight (Dahl, 1992, p. 174); (Leggett, 1995 p. 916).

35 See e.g. Casimir (1977b p. 488), Dahl (1992 p. 174-175), Leggett (1995, p. 924) or Matricon \& Waysand (2003, p. 68 - 70) for discussions of their work.

36 The original German goes as follows: "Wir wollen in diesem Abschnitt untersuchen, wie die oben gefundene Lösung für Supraleiter sich aus derjenigen für gewöhnliche Leiter mit endlicher Leitfähigkeit $\sigma$ durch den Grenzübergang $\sigma \rightarrow \infty$ ergibt".
} 
bances take place reversibly" (London\&London, 1935a, p. 73) (this quote is discussed on page 8). If we accept the Meissner effect, however, the whole superconducting state should be reversible. The Londons' work ${ }^{37}$ now showed them that it was the acceleration equation's differential form that was responsible for the frozen in fields - "one should not use a differential equation like (1) which contains too many possibilities, as it gives nature more freedom than it wants" $1935 \mathrm{a}$, p. 73) — and that dropping it led to a reversible description of the superconducting state:

[The London brothers] realized that the history dependence of the field value is a direct consequence of the presence of time derivatives on both sides of equation $\sqrt{3}\left[\nabla \times \Lambda \frac{d \mathbf{J}}{d t}=-\frac{1}{c} \frac{d \mathbf{H}}{d t}\right]$, while the desired decay of the field on the length scale $\lambda$ follows from the curl operator on the left-hand side of Eq. 3 . Instead of using Eq. 3], they simply proposed to drop the time derivatives, leading to a new material's equation for superconductors: $\nabla \times \Lambda \mathbf{J}=-\frac{1}{c} \mathbf{H}$. (Schmalian, 2011, p. 49)

In this way, their analysis of the acceleration equation suggested an equation that did not entail the irreversibility of the superconducting transition, by showing them which part of the equation was unwanted because it led to history-dependence, and which part led to the desired decay of the field. It also brought them to their alternative for the perfect-conductivity conception: "the idea of an infinite conductivity is replaced by the conception that, by a general relation, the supracurrents are connected with the magnetic field. The latter penetrates into the supraconductor only as deep as the supracurrent flows" (London, 1936, p. 991).

As such, the London brothers were concerned with the acceleration equation not because it relied on a problematic ferromagnetic conception, but rather because it offered them a way to overcome what they took to be the central issue raised by the Meissner effect, namely the perfect

\footnotetext{
37 Heinz London already had quite some understanding of the equation, because in his $\mathrm{PhD}$ thesis, he elaborated "a notion of finite penetration depth in superconductors due to the inertia of electrons, similar in concept to that of Becker, Heller, and Sauter" (Dahl 1992 p. 226). Fritz was very enthousiastic about this work (Dahl 1992 p. 228). See also Matricon and Waysand (2003 p. 68 - 70) for a discussion of the relation between Heinz's PhD and the work by Becker, Heller, and Sauter.
} 
conductivity-conception and the irreversibility-idea it entailed. An important point to make here, however, is that this interpretation of the issues raised by Meissner and Ochsenfeld's experiment was not shared by everybody. While Gorter, for example, also saw Meissner and Ochsenfeld's experiment as the confirmation of the assumption that $B=0$, he did not conclude from this that perfect conductivity should therefore be given up. He rather took it to indicate that "a superconductor could be regarded as being a perfect conductor as well as a perfect diamagnet", which also entailed that "the phenomenon turned out to be reversible and thermodynamics could be justifiably used" (Gavroglu, 1995, p. 116) (see also (Dahl, 1992, p. 186 - 187)). Without this assumption that the problem was with perfect conductivity, it was not always perfectly clear what the Londons' work came down to, as Gorter indicated in his reminiscences of his superconductivity work in Leiden 38

\footnotetext{
Though the elegance of the [Londons'] treatment was certainly recognized, I am afraid that its importance was underestimated somewhat in Holland. It was sometimes considered as a completion of Becker, Heller, and Sauter's formalism by fixing the integration constant of the magnetic field according to the Meissner effect. The discussion of the implications and the background of the equation gave emphasis to the diamagnetic aspect of superconductivity, while the complete disappearance of the electrical resistance at most appeared as a secondary quality, a shift of values which was not immediately appreciated everywhere. (Gorter 1964 p. 6)
}

The central issue is hence not with the acceleration equation being based on the ferromagnetic conception, but rather with the perfect conductivity conception. That this conception should be abandoned is thus not a consequence of Meissner and Ochsenfeld's experiment, not even in combination with Gorter and Casimir's thermodynamic work, but an assumption made by the

38 A similar reading of the Londons' work can also be found in A. H. Wilson's (1936) review article. He described the Londons' work as offering "the most promising line of attack" for understanding the mechanism of superconductivity (1936, p. 269), but he also noted that "[t]he great defect in the theory is that it is purely formal, and it is probable that no great advance can be made without a microscopic derivation of equation [8] or an understanding of what happens during the transition to the superconducting state" (1936 p. 270). 
London brothers. And it is by working on the acceleration equation under this assumption that the Londons arrived at their new equations.

The Diamagnetic Insight A final issue concerns the assumption that what guided the London brothers to their new account was the (local or structural) knowledge, provided by Meissner and Ochsenfeld's experiments, that superconductors are (analogous to) diamagnets. Fritz and Heinz themselves described the diamagnetic insight as follows: "In contrast to the common idea, that in a superconductor current can exist without participation of a field, the superconducting current is characterized here as a kind of diamagnetic volume current. The superconducting current is maintainted by a magnetic field, which itself can be generated by the current" $1935 \mathrm{c}$, p. 341; personal translation) 39

This immediately shows that the diamagnetic conception was not provided by Meissner and Ochsenfeld's experiment. The diamagnetic insight was rather provided by the new equation 8 which, in contrast to earlier views, characterized the superconducting current in terms of the magnetic field. As such, we should not take this conception at the time to form any kind of experimental knowledge. It instead provided something that the Londons themselves described as "a programme" $1935 \mathrm{a}$, p. 87) for overcoming Bloch's impossibility-result. For if the current was maintained by a magnetic field, Bloch's result would not apply, since "Bloch's theorem deals with a system without external electric or magnetic field[, and] [w]e see that in a magnetic field this theorem evidently does not hold" (London, 1935b, p. 26).

The diamagnetic conception thus offered a programme for the development of a theory of superconductivity which could evade Bloch's theorem. It indicated, moreover, that such a theory

\footnotetext{
39 The original German goes as follows: "Im Gegensatz zu der üblichen Vorstellung, dass im Supraleiter Ströme ohne Mitwirkung eines Feldes bestehen können, ist in der hier vorgeschlagenen Formulierung der Suprastrom als eine Art diamagnetischer Volumenstrom gekennzeichnet. Der Suprastrom wird durch ein Magnetfeld aufrechterhalten, welches seinerseits von dem Strome selbst erzeugt sein kann."
} 
had to be formulated in quantum mechanical terms, because since "[w]e know that diamagnetism is specific to quantum mechanics[,] [w]e cannot explain this phenomenon by any mechanism of classical mechanics" (London, 1937b, p. 18; personal translation) ${ }^{40}$ The Londons started elaborating the programme at the end of their (1935a) paper on the basis of a formal similarity between their new equations and "Gordon's formulae for electric current and charge in his relativistic formulation of Schrödinger's Theory" (London\&London, 1935a, p. 86), and carried it out further in Fritz's Royal Society lecture (1935b, p. $31-33)$ and in another joint article 1935c, p. $348-354)$. Daniela Monaldi summarizes this work at the time as follows:

\footnotetext{
A formal analogy pointed the way to theoretical explanation. The relation between current density and magnetic field in a superconductor could be identified with the quantum-mechanical expression of the current density of electrons in the metal, and hence the positive constant could be interpreted in terms of the number of electrons per $\mathrm{cm}^{2}$, if the lowest state of the electrons was separated by a finite gap from the excited states. Under this condition, the electron wave functions would not be significantly altered by the presence of a weak magnetic field. The super-current would then not be a current that can persist in absence of an electric field, but "a kind of diamagnetic volume current", maintained in the superconductor by its own magnetic field. This analogy, obviously, did not amount to a theory, but it was taken "as indicating roughly a programme" that required "a detailed quantum mechanical investigation" (London\&London, 1935a, p. 87). (Monaldi, 2017, p. 39)
}

Important, however, is that the Londons were also still somewhat hesitant about this diamagnetic interpretation of their new equations. In a discussion of their equation 99 linking electric field to charge density, they pointed out, for example, that "the diamagnetic analogy should not be taken too literally" $1935 \mathrm{c}$, p. $350-351$ ), since it suggests an incorrect eigenfunction in the case of the application of an electrostatic field 41 The diamagnetic conception, in its early days, was therefore mostly a programme, of which it was not known completely how it was to be understood. It is

$\overline{40}$ The original French goes as follows: "On sait que le diamagnétisme est une particularité de la mécanique quantique. On ne peut expliquer ce phénomène par aucun mécanisme de la mécanique classique."

41 The original German goes as follows: "Betrachten wir nun die Gleichungen [[9]], so ist zu bemerken, dass die Analogie mit dem diamagnetischen Atom nicht zu wörtlich genommen werden kann. Zur Begründung von [ [9]] 
mostly in later years, according to Monaldi (2017, p. 39), that it became central to Fritz London's work on superconductivity, superfluidity and on quantum mechanisms of macroscopic scale 42

At first, the diamagnetic conception was primarily a programmatic suggestion by the Londons' new equations that was rather ad hoc, as Gavroglu and Goudaroulis put it, since it was only through later work that its meaning was formulated: "before the invention of the new - but ad hoc - auxiliary hypotheses in the old programme, before the unfolding of the new programme, and before the discovery of the new facts indicating a progressive problemshift in the latter, the objective relevance of the Meissner-Ochsenfeld experiment was very limited" (1989, p. 126). We should therefore be careful in projecting this later interpretation back on Fritz and Heinz's (1935a) work. What is clear, however, is that it was not the case that at the time the Meissner effect in itself showed that a superconductor is a kind of diamagnet and that this conception prompted the correction of the acceleration equation (Suárez, 1999, p. 186), nor that the Meissner effect "drove a shift in the overriding analogy, from that with ferromagnetism in the case of the old 'pre-Meissner' model, to that with diamagnetism in the case of London and London's" Bueno et al. 2012a, p. 44) and that the "microscopical interpretation of the London-London model [... ] was set, in large part, by the diamagnetic analogy" (Bueno et al. 2012a, p. 43).

wäre es notwendig zu zeigen, dass die Eigenfunktion des Supraleiters auch durch ein elektrostatisches Feld in erster Näherung keine Störung erfährt. Bei einem gewöhnlichen diamagnetischen Atom ist dies nicht zutreffend. Die Eigenfunktion eines solchen erfährt vielmehr eine Störung, welche proportional der angreifenden elektrischen Feldstärke ist."

42 This may now also explain the fact, pointed out in footnote 20 that Fritz London, in his (1937a) article, drew a much closer connection between Meissner and Ochsenfeld's experiment and diamagnetism than in their earlier work, since by that time his work on the diamagnetic programme had already progressed much further. 


\section{Concluding Remarks: Philosophically Evaluating the London \& London Debate}

The CSS-FLBD debate is concerned with whether the construction of the London model was theory-driven or not. The importance of this issue lays in the fact that it is situated within a broader debate on scientific representation: is it general theories or particular models that can be said to represent a particular phenomenon?

According to CSS, the construction of the model was not theory- but phenomenologicallydriven: it was the local and particular knowledge provided by the phenomenon itself that guided, in a piecemeal and mediating way, the construction of the model. The construction was thus autonomous from theory in methods and aims - electromagnetic theory did not tell the London brothers how to fill in the holes in the acceleration equation -, and it therefore provides an argument against theory-driven accounts: "[t]heory served to help construct the new model but the model, and the accompanying claims about superconductivity and its sources, were not already there contained in the theory - perhaps only in some highly abstract form - waiting to be extracted" (Cartwright\&Suárez, 2008, p. 63). Because it was not theory that told them how to construct an electromagnetic model, the case also argues, according to CSS, that it is models, rather than abstract and general theoretical claims, that represent: "Physics does aim to represent the world, but it represents it not in its theories but in its models" (Cartwright et al. 1995, p. 139). Theories only serve as tools for the construction of such models.

For FLBD, on the other hand, theory did play an important role: the phenomenon provided structural knowledge that allowed for the importation of theoretical structures that guided the London brothers. As such, the construction was not autonomous from theory, and it therefore does not provide an argument against theory-driven views: "the fact that this [piecemeal] borrowing was informed by theoretical factors, as well as empirical, undermines the inter-twined claims that the London and London case is an example of phenomenological model building and 
that it exemplifies model building that is independent of theory in methods and aims" (2012a, p. 43). The case thus argues, according to FLBD, that theories also represent: "if models can be said to represent then so can theories" (French\&Ladyman, 1997, p. 367).

Underlying the debate, we have seen, is a shared historical narrative. Both sides assume that Meissner and Ochsenfeld's experiment provided the insight that the superconducting phenomenon is to be understood in diamagnetic rather than ferromagnetic terms, and that this insight guided the London brothers in the development of their equations as a replacement for the acceleration equation. Within this narrative, the focus is then on how we should understand this guiding insight.

The narrative, however, is defective. It is not the case that Meissner and Ochsenfeld's experiment in itself showed that superconductors are not ferromagnetic but rather diamagnetic. The experiment rather suggested that the transition to the superconducting state was reversible. This brought the London brothers to postulate the Meissner effect, i.e. Meissner and Ochsenfeld's experiment combined with its replications and Gorter and Casimir's thermodynamic work, as the ideal case. On the assumption that it was the perfect conductivity approach that was responsible for the irreversibility-idea and the frozen-in fields, this postulate then acted as a constraint on their work on the acceleration equation, which suggested their new equations (8) and (9). According to these equations, the superconducting current only arises in the presence of a magnetic field. This, together with a formal similarity between these new equations and Gordon's formulae for electric current and charge, then suggested the diamagnetic programme, i.e. a way to overcome Bloch's theorem and to elaborate a theory of superconductivity. At the time, however, it was not completely clear how literally this suggestion was to be read, and it was mostly through Fritz London's later work that its meaning could be elaborated.

The historical issues with the narrative indicate that both sides approach the case too strictly in terms of a specific philosophical conception of representation. Both assume, more specifically, 
that what the Londons achieved in (1935a) was the construction of an electromagnetic model that represented the phenomenon of superconductivity as diamagnetic. This reading entails that the primary question becomes how this representational relation between the diamagnetic insight provided by experiment and the diamagnetic content of the London's equation is to be characterized: in terms of mediation or theoretical correspondences 43

The problem with the way in which both CSS and FLBD approach this issue, I have argued, is that they conduct it in a confrontational mode: the historical episode is to function as evidence for their respective philosophical theories. This allows both sides to keep on claiming that the historical narrative in fact acts as a case for their claims. In order to make progress, I have proposed to approach the debate in a different way, following the suggestion, by Schickore and others, to develop and elaborate historical and philosophical understanding in an integrated and cyclical way. Proceeding in this way has led me to the historical insights discussed in the previous section. The question now arises what these insights can tell us about the philosophical topic of representation. In order to address this issue, I will now elaborate a tentative idea suggested by the following aspects of the historical episode: that at the time it was not clear which insight Meissner and Ochsenfeld's experiment was supposed to provide, and that it was not clear in how far the Londons' new model actually provided a new representation.

With respect to the first point, we should not always take experiments such as Meissner and Ochsenfeld's to directly provide insight into a phenomenon. Instead, the question of what kind of phenomenon the experiment is trying to provide insight into, is itself open for debate at the time of the experiment. It was only through the intentional act of postulating the Meissner effect, which comprised Meissner and Ochsenfeld's experiment and its replications as well as Gorter's and Casimir's work, that the London brothers stabilized a particular experimental phenomenon.

43 See especially (Cartwright\&Suárez 2008 p. 64-68) and Bueno et al. 2012b p. 102) for a thorough discussion of how both sides interpret the idea of independence from theory. 
But other stabilizations were also possible: Gorter, for example, took the Meissner effect to indicate that superconductors are both perfect conductors and perfect diamagnets. As such, an experimental phenomenon should not be taken as something revealed by an experiment, but rather as something that is constituted over time through a process that involves, among other things, elaborating theory, replicating experiments and engaging with alternative views.

A second point is that we should not always assume that the meaning of newly formulated equations, at the time of their presentation, is already settled. How the Londons' new account was to be read was itself open for different interpretations: the London brothers characterized the diamagnetic suggestion as mostly a programme for future research, which, they claimed at the time, should not be taken too literally; others, such as Gorter and Wilson, mainly saw it as merely a new formalism (see page 30. Moreover, it was not even completely clear at the time in how far the Londons' work should be taken as valid: Meissner, for example, in a letter to F. Heidenreich from 1935 about measurements carried out by Heidenreich, stated that they lead to a conclusion "which seems to me not to be favorable to the general validity of the hypothesis of Gorter and Casimir and therefore also of the theory given by the Londons" (Dahl, 1992, p. 222) 44 This also shows that it was not completely clear in how far the Londons' proposal differed from other proposals 45 It was mostly through Fritz London's later work that the meaning of the equations, as providing a novel account in terms of a substantial connection between superconductivity and diamagnetism, was crafted and stabilized. This suggests that the interpretation of a model - that which it represents - should not be taken as something established at the moment when it is constructed, but rather as something that is historically elaborated over time in its application

\footnotetext{
44 Meissner repeats this claim during a presentation of his later results at the Royal Society Meissner 1935 p. 15).

45 A similar claim can be found in Smith and Wilhelm's 1935 p. 270) review article, in which they presented their vortex current theory. This theory, they claimed, seems to be experimentally indistinguishable from the Londons' theory, even though it retains the local validity of the acceleration equation.
} 
to other, adjacent issues, in such a way that it can then be successfully projected backwards on the 'moment of construction'.

These points now raise two issues with the way in which CSS and FLBD address the question of representation. The first concerns the fact that they try to address it by investigating what kind of connection there is between the phenomenon laid bare by Meissner and Ochsenfeld's experiment and the conception underlying the Londons' new equation: should it be seen in terms of mediation or rather of structural correspondence? What the above shows, however, is that it is difficult to speak about the connection between the phenomenon and the model, since neither side of the connection should be seen as already stable in itself, but rather as constructed ensembles of different elements - experiments, theories, assumptions, models, etc. - that changed over time. The second concerns the fact that they focus solely on how the London brothers themselves saw the construction of their own model. What the points raised above show is that at the time there were also other perspectives on the way in which the Londons' new account related to already exisiting experiments and theories, and also other possible accounts of the meaning of Meissner and Ochsenfeld's experiments for the study of superconductors.

We have seen how the debate between CSS and FLBD is shaped by a particular philosophical conception of how scientific representation should be studied: as the discovery of a connection between a given experimental phenomenon and the meaning of the new equations. This approach clashes with the historical episode, but at the same time the episode also suggests an alternative way to study scientific representation: as the establishment, over time, of a connection between historically stabilized constellations of different elements that, through discussion and engagement with alternative views and approaches, come to constitute phenomenon and meaning.

Important to stress here is that my philosophical points about representation should not be seen as any kind of definitive alternative account provided by the historical case. In line with the approach sketched by Schickore and others, they are rather to be seen as an invitation for 
further historical and philosophical research. One particular issue that suggests itself for further elaboration is the idea of the stabilization of phenomenon and meaning: how are we to understand it exactly? An interesting philosophical take on this issue can be found in Uljana Feest's (2011) work on the stabilization of phenomena. This process, she claims, involves two central aspects. The first she calls the skill-aspect, which concerns the way in which scientists come to the idea that they are dealing with a phenomenon in reality. It has to do "with the ability to make empirical results physically stable, i.e., to "make an experiment work", or make an instrument reliably reproduce particular results, where this clearly involves the ability to recognize that the experiment/instrument did in fact work" (Feest, 2011, p. 59 - 60). The second she calls the validation-aspect, which concerns the establishment of agreement on the phenomenon that is studied: "[t]he focus here is on the question of how scientists (individually or collectively) come to converge in their delineation and classification of relevant phenomena" (Feest, 2011, p. 60). What is stabilized through skill and validation, she then claims by means of a discussion of memory research, is a fit between a surface phenomenon, i.e. empirical data patterns, and a hidden phenomenon, which is more removed from empirical data 46 A central point here is that what this stable fit relates can change over time: her discussion of memory research, for instance, provides "examples of how the surface regularity is instrumental in an investigation of a hidden regularity, which in turn may change the ways in which the surface regularity is classified" (Feest, 2011, p. 70).

Feest's work suggests that the way in which the Londons' equations came to be seen as representing superconductors as diamagnets of some kind involved the stabilization, over time,

\footnotetext{
46 Feest's conception of phenomena here is influenced by James Bogen and James Woodward's (1988) distinction between data and phenomena. On Feest's view, surface phenomena are to be found in the data collected in a particular experiment, while hidden phenomena are the phenomena that are instantiated by these data and explained by theory.
} 
of a fit between a surphace phenomenon to be found in the experimental data (Meissner and Ochsenfeld's results, ...) and a hidden phenomenon elaborated through more theoretical work (Fritz London's work on superconductivity, superfluidity, quantum mechanisms of macroscopic scale, ...). And this stabilization involved both skill (e.g. the attempts to replicate Meissner and Ochsenfeld's experiment in an adequate way) and validation (e.g. the Londons' work being picked up by Bardeen, Schrieffer and Cooper). This shows new ways to study the stabilization of phenomenon and meaning in more historical detail, e.g. by looking at how both Meissner and Ochsenfeld's experiments and the Londons' work was discussed, interpreted and used by other scientists. While I have touched on these topics, they are mainly the subject of future work 47 For now, the main conclusion to be drawn from this is that approaching the London \& London case not in a confrontational but in what Schickore (2011, p. 477) calls a hermeneutical way, allows us to study the issue of representation in a way that more adequately integrates history and philosophy of science.

Acknowledgements The author would like to thank Bert Leuridan, Mieke Boon, Brandon Boesch, Laura Georgescu, and the audiences at the OZSW Graduate Conference in Theoretical Philosophy 2016 (University of Twente), the GRAT Workshop 2016 (University of Antwerp), and the SPSP Conference 2016 (Rowan University).

47 This approach suggests for example, the following topics of further historical-philosophical research: the way in which Meissner himself, in collaboration with Heidenreich after Ochsenfeld moved to a new academic position, attempted to replicate his own experiments, and how these were received within the community at the time (see (Dahl, 1992 p. $195-208)$ ); the way in which the Londons' new account led to a prediction for the precise penetration depth of the superconducting current, and how this was tested experimentally by David Shoenberg (Matricon\&Waysand, 2003 p. 64); or how the Londons' 1935a) work led Heinz to elaborate a theory that provided a way to study the differences between superconducting pure metals and superconducting alloys (Dahl, 1992 , p. $230-231)$. All these topics allow us to study, more specifically, how both skill and validation contributed to the emergence of a stable fit between experimental results and theoretical interpretations over time. 


\section{References}

Arabatzis, T. \& Schickore, J. (2012). Ways of integrating history and philosophy of science. Perspectives on Science, 20(4): $395-408$.

Bailer-Jones, D. (2009). Scientific Models in Philosophy of Science. University of Pittsburgh Press.

Becker, R. Sauter, F. and Heller, G. (1933). Uber die Stromverteiling einer Supraleitenden Kugel. Zeitschrift für Physik 85(11): 772 - 787.

Bogen, J. \& Woodward, J. (1988). Saving the phenomena. The Philosophical Review, XCVII(3): $305-352$.

Braunbek, W. (1934). Die Ausbreiting elektromagnetischer Wellen in einem Supraleiter. Zeitschrift für Physik 87(7): 470 - 483.

Brillioun, L. (1935). Supraconductivity and the Difficulties of its Interpretation. Proceedings of the Royal Society A 152(875): $19-21$.

Bueno, O. \& French, S. \& Ladyman, J. (2002). On Representing the Relationship Between the Mathematical and the Empirical. Philosophy of Science 69: 497 - 518.

Bueno, O. \& French, S. (2011). How Theories Represent. British Journal for Philosophy of Science 62(4): $857-894$.

Bueno, O. \& French, S. \& Ladyman, J. (2012). Models and Structures: Phenomenological and Partial. Studies in History and Philosophy of Modern Physics 43: 43 - 46.

Bueno, O. \& French, S. \& Ladyman, J. (2012). Empirical Factors and Structure Transference: Returning to the London Account. Studies in History and Philosophy of Modern Physics 43: $95-104$.

Burian, R. M. (2001). The dilemma of case studies resolved: The virtues of using case studies in the history and philosophy of science. Perspectives on Science, 9(4): $383-404$. 
Burian, R. M. (2002). Comments on the precarious relationship between history and philosophy of science. Perspectives on Science, 10(4): 398 - 407.

Cartwright, N. \& Shomar, T. \& Suárez, M. (1995). The Tool Box of Science: Tools for the Building of Models with a Superconductivity Example. Poznán Studies in the Philosophy of the Sciences and the Humanities 44: $137-149$.

Cartwright, N. \& Suárez, M. (2008). Theories: Tools versus Models. Studies in History and Philosophy of Modern Physics 39: $62-81$.

Casimir, H. (1977). Superconductivity. In: Weiner, C. (ed.). History of Twentieth Century Physics. Proceedings of the International School of Physics "Enrico Fermi".

Casimir, H. (1977). Superconductivity and Superfluidity. In: Mehra, J. (ed.). The Physicist's Conception of Nature. Springer.

Chandrasekhar, B. S. (1969). Early Experiments and Phenomenological Theories. In: Parks, R. D. (ed.). Superconductivity: Volume 1. Marcel Dekker, Inc.

Chang, H. (2012). Beyond Case-Studies: History as Philosophy. In: Mauskopf\&Schmaltz (2012). Da Costa, N. \& French, S. (2000). Models, Theories, and Structures: Thirty Years on. Philosophy of Science 57: $116-127$.

Da Costa, N. \& French, S. (2003). Science and Partial Truth: A Unitary Approach to Models and Scientific Reasoning. Oxford university Press.

Dahl, P. F. (1992). Superconductivity: Its Historical Roots and Development from Mercury to the Ceramic Oxides. American Institute of Physics.

Essén, H. \& Fiolhais, M. C. N. (2012). Meissner effect, diamagnetism, and classical physics - a review. American Journal of Physics, 80: $164-169$.

Feest, U. (2011). What exactly is stabilized when phenomena are stabilized? Synthese, 182: 57 $-71$. 
Feynman, R. (1964). The Feynman Lectures on Physics Volume II: Mainly Electromagnetism and Matter. Adison-Wesley.

French, S. \& Ladyman, J. (1997). Superconductivity and Structures: Revisiting the London Account. Studies in History and Philosophy of Modern Physics 28(3): 363 - 393.

French, S. (1999). The Phenomenological Approach to Physics. Studies in History and Philosophy of Modern Physics 30: 267 - 281.

French, S. \& Ladyman, J. (1999). Reinflating the Semantic Approach. International Studies in the Philosophy of Science 13: 103 - 121.

French, S. (2010). Keeping Quiet on the Ontology of Models. Synthese 172(2): 231 - 249.

Gavroglu, K. \& Goudaroulis, Y. (1984). Some methodological and historical considerations in low temperature physics: The case of superconductivity 1911-57. Annals of Science, 41(2): 135 $-149$.

Gavroglu, K. \& Goudaroulis, Y. (1989). Methodological Aspects of the Development of Low Temperature Physics 1881 - 1956: Concepts out of Context(s). Kluwer Academic Publishers.

Gavroglu, K. (1995). Fritz London: A Scientific Biography. Cambridge University Press.

Gorter, C. (1933a). Some Remarks on the Thermodynamics of Supraconductivity. Archives du Musèe Teyler 7: 378 - 386 .

Gorter, C. (1933b). Theory of Supraconductivity. Nature 132: 931.

Gorter, C. \& Casimir, H. (1934). On Supraconductivity I. Physica 1: 306 - 320.

Gorter, C. J. (1964). Superconductivity until 1940 In Leiden and As Seen From There. Reviews of Modern Physics, 36(1): $3-7$.

Hoddeson, L. H. \& Baym, G. (1980). The Development of the Quantum Mechanical Electron Theory of Metals: 1900-28. Proceedings of the Royal Society of London A, 371(1744): 8 - 23.

Hoddeson, L. H. Baym, G. \& Eckert, M. (1987). The Development of the Quantum Mechanical Electron Theory of Metals: 1928 - 1933. Reviews of Modern Physics, 59(1): 287 - 327. 
Kamerlingh Onnes, H. (1913). Commun. Kamerlingh Onnes Lab., Tech. Rep. 34b, Univ. Leiden.

Kamerlingh Onnes, H. \& Tuyn, W. (1924). Nouvelles expériences avec les supraconducteurs. In: Institut international de physique Solvay, (ed.), Conductibilité électrique des métaux et problèmes connexes: rapports et discussions du quatrième Conseil de physique tenu à Bruxelles du 24 au 29 avril 1924. Gauthier-Villars.

Keesom, W. H. \& Kok, J. A. (1934). Measurement of the latent heat of thallium connected with the transition, in a constant external magnetic field, from the supraconductive to the non-supraconductive state. Commun. Kamerlingh Onnes Lab., Tech. Rep. 203e, Univ. Leiden.

Kinzel, K. (2015). Narrative and evidence. How can case studies from the history of science support claims in the philosophy of science? Studies in History and Philosophy of Science, 49 : $48-57$.

Kinzel, K. (2016). Pluralism in Historiography: A Case Study of Case Studies. In: Sauer\&Scholl (2016).

Kittel, C. (2005). Introduction to Solid State Physics Eight Edition. John Wiley \& Sons, Inc.

Knuuttila, T. \& Loetgers, A. (2016). Contrasting Cases: The Lotka-Volterra Model Times Three. In: Sauer\&Scholl (2016).

Ladyman, J. (1998). What is Structural Realism?. Studies in History and Philosophy of Science $29(3): 409-428$.

Ladyman, J. (2002). Understanding Philosophy of Science. Routledge.

Landry, E. (2007). Shared structure need not be shared set-structure. Synthese 158:1 - 17.

Le Bihan, S. (2012). Defending the Semantic View: What it Takes. European Journal for Philosophy of Science 2: $249-274$.

Leggett, A. J. (1995). Superfluids and Superconductors. In: Brown, L. Pippard, B. \& Pais, A. (eds.). Twentieth Century Physics (Volume 2). CRC Press. 
London, H. (1934). Production of Heat in Supraconductors by Alternating Currents. Nature 133: $497-498$.

London, F. \& London, H. (1935a). The Electromagnetic Equations of the Supraconductor. Proceedings of the Royal Society A149: $71-88$.

London, F. (1935). Macroscopical Interpretation of Supraconductivity. Proceedings of the Royal Society A 152(875): $24-34$.

London, F. \& London, H. (1935b). Supraleitung und Diamagnetismus. Physica 2(1): $341-354$.

London, F. (1936). Electrodynamics of Macroscopic Fields in Supraconductors. Nature 137: 991 $-992$.

London, F. (1937a). A New Conception of Supraconductivity. Nature 140: $793-796,834-836$.

London, F. (1937b). Une conception nouvelle de la supra-conductibilité: conférences faites à l'Institut Poincaré, Paris. Hermann.

Lorentz, H. A. (1924). Application de la théorie des électrons aux propriétés des métaux. In: Institut international de physique Solvay, (ed.), Conductibilité électrique des métaux et problèmes connexes: rapports et discussions du quatrième Conseil de physique tenu à Bruxelles du 24 au 29 avril 1924. Gauthier-Villars.

Lutz, S. (2017). What Was the Syntax-Semantics Debate in the Philosophy of Science About? Philosophy and Phenomenological research, 95(2): $319-352$.

Matricon, J. \& Waysand, G. (2003). The Cold Wars: A History of Superconductivity. Translated from French by Charles Glashausser. Rutgers University Press.

Mauskopf, S. \& Schmaltz, T. (2012). Integrating History and Philosophy of Science: Problems and Prospects. Springer.

Meissner, W. \& Ochsenfeld, R. (1933). Ein neuer Effekt bei Eintritt der Supraleitfähigkeit. Die Naturwissenschaften 21: 787 - 788. In: Forrest, A. (1987). Meissner and Ochsenfeld Revisited. European Journal of Physics 4(2): 117 - 120. 
Meissner, W. (1935). The Magnetic Effects Occurring on Transition to the Supraconducting State. Proceedings of the Royal Society A 152(875): 13 - 15.

Mendelssohn, K. \& Babbitt, J. D. (1935). Magnetic behaviour of supraconducting tin spheres. Proceedings of the Royal Society of London, 151(873): 316 - 333.

McMullin, E. (1985). Galilean Idealizations. Studies in History and Philosophy of Science 16(3): $247-273$

Monaldi, D. (2017). Fritz London and the scale of quantum mechanisms. Studies in History and Philosophy of Modern Physics, 60: 35 - 45.

Morgan, M. \& Morrison, M. (1999). Models as Mediators: Perspectives on Natural and Social Science. Cambridge University Press.

Morrison, M. (2008). Models as Representational Structures. In: Hartmann, S. et al. (Eds.). Nancy Cartwright's Philosophy of Science. Routledge.

Pietsch, W. (2016). Two Modes of Reasoning with Case Studies. In: Sauer\&Scholl (2016).

Pitt, J. C. (2001). The dilemma of case studies: Towards a heraclitian philosophy of science. Perspectives on Science, 9(4): $373-382$.

Redhead, M. (1980). Models in Physics. The British Journal for the Philosophy of Science 31(2): $145-163$.

Rjabinin, J. N. \& Schubnikow, L. (1935). Über die Abhängigkeit der magnetischen Induktion des supraleitenden Blei vom Feld. Physikalischer Zeitschrift der Sowjet Union, 6: 557 - 568.

Sauer, T. \& Scholl, R. (2016). The Philosophy of Historical Case Studies. Springer.

Schickore, J. (2011). More Thoughts on HPS: Another 20 Years Later. Perspectives on Science, 19(4): $453-481$.

Schindler, S. (2007). Rehabilitating Theory: Refusal of the 'Bottom-Up' Construction of Scientific Phenomena. Studies in History and Philosophy of Science 38: 160 - 184. 
Schmalian, J. (2011). Failed Theories of Superconductivity. In: Cooper, L. N. \& Feldman, D. (eds.). BCS: 50 Years. World Scientific Publishing Co.

Scholl, R \& Räz, T. (2016). Towards a Methodology for Integrated History and Philosophy of Science. In: Sauer\&Scholl (2016).

Smith, H. G. \& Wilhelm, J. O. (1935). Superconductivity. Reviews of Modern Physics 7(4): 237 $-271$.

Suárez, M. (1999). The Role of Models in the Application of Scientific Theories: Epistemological Implications. In: Morgan\&Morrison (1999).

Tinkham, M. (1996). Introduction to Superconductivity Second Edition. McGraw-Hill.

Wilson, A. H. (1936). Superconductivity and the theory of metals. Reports on Prgoress in Physics, 3: $262-271$. 